\title{
Offline Induction Machine Parameters Identification Suitable for Self-commissioning
}

\author{
Tomáš Koštál \\ Department of Electric Drives and Traction \\ Faculty of Electrical Engineering, Czech Technical University in Prague \\ Prague, Czech Republic \\ kostatom@fel.cvut.cz
}

\begin{abstract}
Precise control methods of the electric drives with induction machines like field oriented control (FOC) or direct torque control (DTC) need an accurate model of the machine they control. Certain parameters of the model have to be obtained with sufficient accuracy before the drive can be put into the operation. This article concerns an offline parameter identification method that is suitable for on-site drive commissioning as it does all the necessary measurements only with the means of the power converter of the drive.
\end{abstract}

Keywords - induction motor drive; parameter identification; self-commissioning

\section{INTRODUCTION}

Induction machine became the most common electromechanical converter in various applications. In lots of these applications there are high demands on precise control of the drive. Two principal control methods crystalized in last decades to be deployed in such drives with induction machines. These are Direct Torque Control (DTC) and Field oriented control (FOC). Both of these methods can be characterized by usage of a mathematical model which requires knowledge of certain parameters of the induction machine. Efficiency and dynamic properties of the drive can be significantly lowered or even completely deteriorated if incorrect parameter values of the model are deployed. At least some knowledge of the machine parameters is needed to enable start of operation of the drive.

Parameters of the induction machine can vary with temperature, frequency and saturation so it is favorable to respect particular working conditions of the drive. It should be mentioned, that parameters of the same type of the machine can vary up to $10-15 \%$ from the manufacturing process [1], [2], so even if the manufacturer provided these data, it would imply that every single unit still would need to be tested if very accurate values were needed.

Parameters that are usually required involve a stator resistance $R_{\mathrm{s}}$, a rotor resistance $R_{\mathrm{r}}$, a magnetizing inductance $L_{\mathrm{m}}$, a stator leakage inductance $L_{\mathrm{s} \sigma}$ and a rotor leakage inductance $L_{\mathrm{r} \sigma}$. From these parameters, only stator resistance $R_{\mathrm{S}}$ is directly measurable.

Because of those facts, only experimental methods are viable in most of cases. These can be divided into three main groups [1], [4], [5]: standard tests and on-site methods which are further divided into offline and online parameter identification methods.

Standard tests (often called also as conventional methods) are laboratory tests like no-load, locked rotor and conventional DC test [3]. Usage of a sinusoidal voltage sources and special-purpose jigs (e.g. for blocking the rotor of a machine) are the main characteristics that distinguishes them from on-site methods. They are widely used for development and research as well as type tests of manufacturers, but they are not very suitable for commercial usage because of material, time and personnel costs.

On-site methods are a response to the issues of conventional methods that make them often inconvenient for a field application. They attempt to minimize requirements of additional measurement or control devices while still giving results with suitable accuracy. They can be divided into two subcategories, the offline and online parameter identification methods.

Offline methods are deployed for obtaining the required parameters before putting the drive into operation. Some of these methods are able to obtain the parameters at standstill of the drive. These are called self-commissioning methods and they permit the load to be connected to the drive. This has a benefit that such a method can be used before every start of the operation and thus it can be used for some degree of respecting the parameter changes. Methods that need to rotate with the drive to obtain the parameters are called commissioning methods.

For identification of parameters during the operation of the drive, so called online methods were developed. They enable the controller to respect parameter changes continually so that the control of drives with high demands on dynamic properties can be more accurate.

It should be noted, that some authors use different classification (e.g. [7]), but in general they follow an idea of distinguishing methods suitable for parameter identification before and after the drive is put into the operation.

This paper deals with offline method of parameter identification that should be suitable for selfcommissioning. 


\section{METHODS}

\section{A. $\quad$ Standard tests}

Standard tests are well known procedures for laboratory testing of induction machines. They include so called DC test, no-load test and locked rotor test. They are used for obtaining parameters of so called " $T$ " equivalent circuit mentioned in the introduction (Figure 1. ).

DC test is a measurement of the stator resistance $R_{\mathrm{s}}$ by a 4 wire method as the resistance is relatively low. By the no-load test the tested machine is let to run without any load so the currents in the rotor bars are negligible. This enables to obtain sum of magnetizing inductance $L_{\mathrm{m}}$ and stator leakage inductance $L_{\sigma \mathrm{s}}$ as there is no current in the right branch of the equivalent circuit. At the beginning of this test the supply voltage is set to $120 \%$ of the machine's rated value $U_{\mathrm{n}}$ (nominal stator voltage) which is the first point of the measurement. Measured quantities are stator voltage $U_{\mathrm{s} 0}$, phase value of stator current $I_{\mathrm{s} 0}$, and input power $P_{\mathrm{I} 0}$. Following this first point, the voltage is decreased in steps to $25 \%$ of $U_{\mathrm{n}}$.

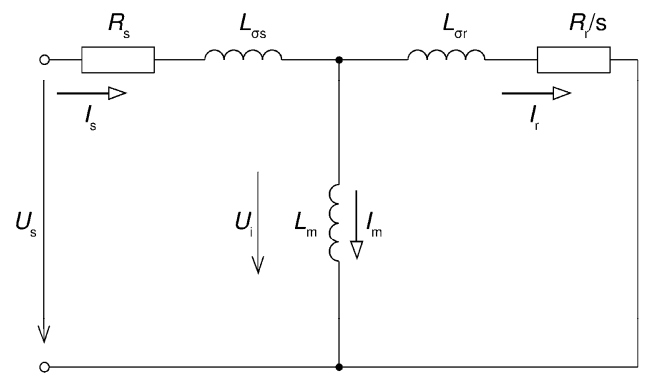

Figure 1. "T" equivalent circuit of an induction machine

For the locked rotor test, machine is prevented to rotate mechanically by fixing the shaft by an appropriate jig and it is supplied from variable AC supply with a constant frequency. While the rotor cannot rotate slip $\mathrm{s}=1$ and impedance of stator - rotor loop is far smaller than the impedance across the middle branch and thus the whole middle branch is neglected as well. After commencing the test, voltage is increased until the current flowing through the machine reaches $120 \%$ of its rated value $I_{\mathrm{n}}$. Voltage is comparatively low as the impedance in this mode is small. Voltage is then lowered until zero while stator voltage $U_{\mathrm{s}}$, stator current $I_{\mathrm{s}}$ and input power are measured. This enables to obtain sum of the stator and rotor leakage inductances $L_{\sigma \mathrm{s}}$ and $L_{\sigma \mathrm{\sigma r}}$ and rotor resistance $R_{\mathrm{r}}$ by separating real and imaginary part of the overall impedance and subtracting the stator resistance. The proportion between the leakage inductances is estimated based on machine construction.

Other common equivalent circuit especially used in case of field oriented control is called inverse $\Gamma$ equivalent scheme (Figure 2. ). Great advantage of this equivalent scheme is that the stator current divides into the currents of the two branches that correspond to flux- and torque- component respectively. To recalculate the parameters of the " $T$ " equivalent circuit to "inverse $\Gamma$ " following relations can be used (1):

$$
\begin{aligned}
& R_{s \Gamma}=R_{s T} \\
& R_{r r e f}=\left(\frac{L_{m}}{L_{m}+L_{r \sigma}}\right)^{2} * R_{r} \\
& L_{\mu}=\left(\frac{L_{m}}{L_{m}+L_{r \sigma}}\right) * L_{m}= \\
& L_{\sigma}=L_{\sigma s}+\frac{L_{m}}{L_{m}+L_{\sigma r}} * L_{\sigma r}
\end{aligned}
$$

where $R_{\mathrm{s}}$ is the stator resistance, $R_{\text {rref }}$ is the rotor resistance referred to the stator, $L_{\mu}$ is the magnetizing inductance and $L_{\sigma \mathrm{\sigma s}}$ is the leakage inductance.

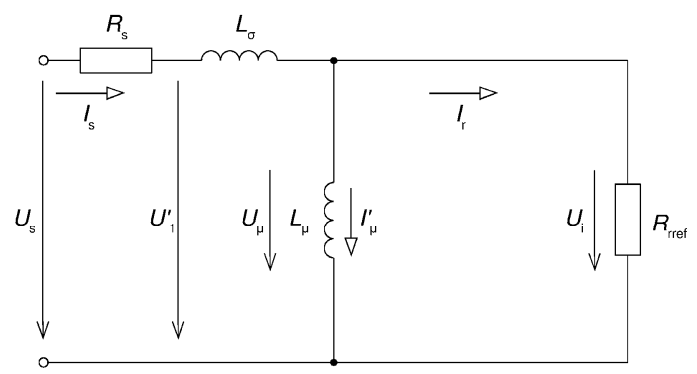

Figure 2. "Inverse $\Gamma$ "equivalent circuit of an induction machine

\section{B. Proposed offline identification method}

Original idea of the proposed method was presented in [7], but some modifications have been done to deploy it on a standard voltage source inverter. The changes were necessary, because the original method was hardly usable on standard hardware equipment, especially because of the LEM sensors. There was a problem to determine exponential in the voltage falling edge, because of the low resolution of measured data. In the part where the exponential was needed to be found the voltage change was very low for the LEM sensors that are dimensioned to hundreds of volts.

\section{1) First part of the measurement}

The measurement procedure has two parts. First part is performed by two voltage pulses of nominal amplitude that are sent to the two of the motor terminals. The short circuited resistance and time constant of the current transient are measured.
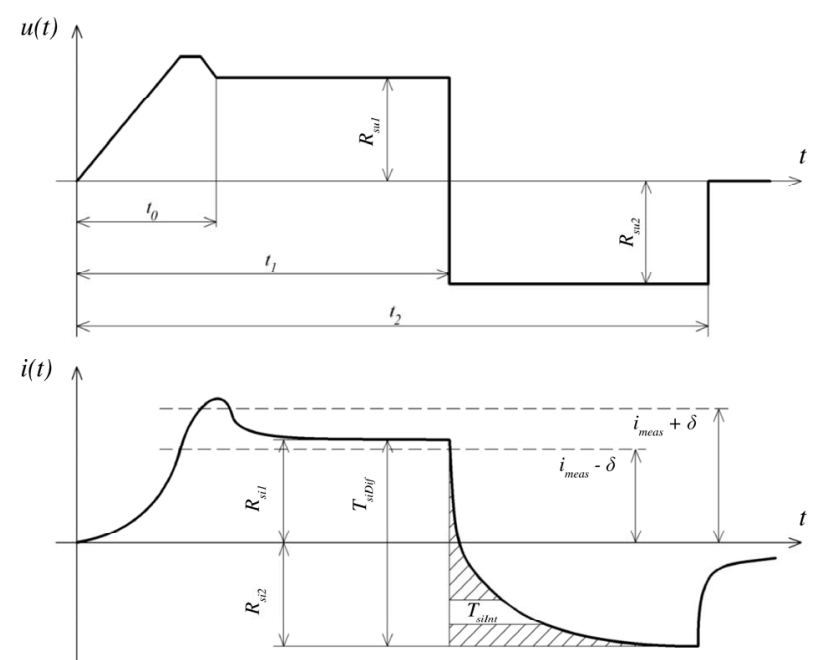

Figure 3. First part of the method 
Four values are measured during the test. The measurement starts with the maximum voltage pulse, which is considered as a positive. Voltage is calculated from the DC link voltage and the duty cycle of the switching devices of the converter while current is measured by converter's current sensors. After reaching the $i_{\text {lim }}$ value of the current (see Figure 3 . ), the terminals of the motor are short circuited. The numeric integration of the current wave $T_{k_{-} i n t}$ and the change in the current value $T_{k_{i} \text { ifif }}$ are measured during the first zero voltage interval. The next measuring interval with the maximum voltage pulse, which is considered as a negative, starts after the current transient reaches the half of the $i_{\text {lim }}$ value. The integral of the voltage $\mathrm{L}_{\mathrm{s}_{-} u \mathrm{Int}}$ and the change in the current $\mathrm{L}_{\mathrm{s} \text { iDif }}$ are measured during the negative voltage interval. The voltage pulse stops after the current has reached the negative value of $i_{\text {lim. }}$. Final zero voltage interval is used only for purposes of checking that the current reaches zero. Short circuit time constant $T_{\mathrm{kx}}$ and leakage inductance $L_{\sigma x}$ are obtained by this measurement as follows:

$$
\begin{gathered}
T_{k x}=\frac{T_{k_{-} i n t}}{T_{k_{-} i D i f}} \\
L_{\sigma x}=\frac{L_{s_{-} u I n t}}{L_{s_{-} i D i f}}
\end{gathered}
$$

These equations are not scaled so the values need to be further recalculated:

$$
T_{k}=\frac{T_{k x}}{f_{v}}, L_{\sigma}=\frac{L_{\alpha x} \cdot s_{u}}{f_{v} \cdot s_{i}}
$$

where $f_{\mathrm{v}}$ is the sampling frequency $(\mathrm{Hz}), \mathrm{s}_{\mathrm{u}}$ is the voltage scale $(\mathrm{V} / \mathrm{bit})$ and $s_{\mathrm{i}}$ is the current scale (A/ bit).

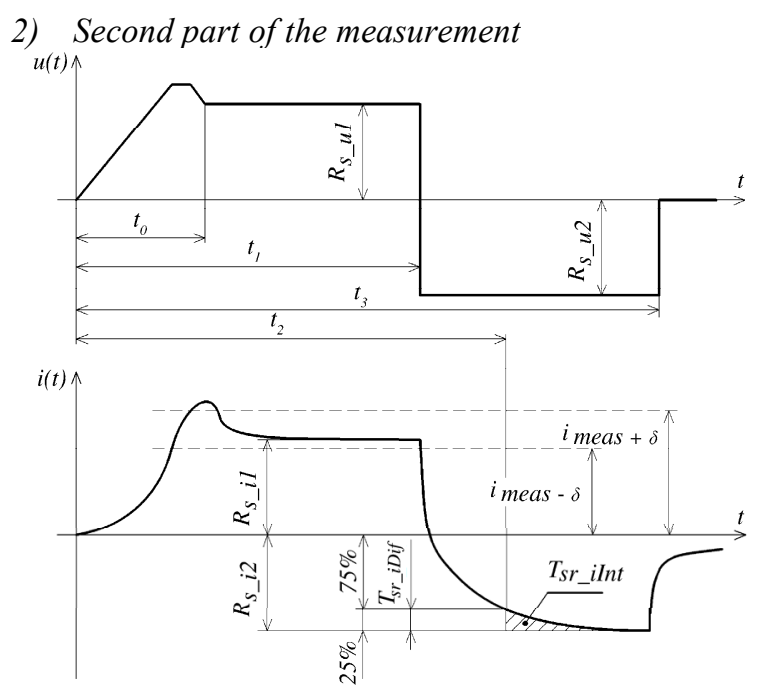

Figure 4. Second part of the method

The measuring scheme starts with the ramp of current, which is needed here to define specific measuring level of the voltage. The voltage level is given by the steady state current. The current must fit the specified interval before the measuring starts. The interval is defined by $\pm \delta$ and by target current $i_{\text {meas }}$ values in the source code. If the current is out of bounds, the duty cycle must be adjusted. After getting the target current the steady state voltage $R_{\mathrm{s} u 1}$ and current $R_{s_{-} \text {i1 }}$ are measured. Both values are filtered via simple first order filter in the source code. The duty cycle is not changed here until the specified measuring time interval $\left(t_{1}-t_{0}\right.$ in Figure 4 . $)$ is reached. The opposite level voltage (duty cycle) is set at the input of the motor then.

The transient of the current starts after setting the opposite voltage step. The immediate value of the current is checked. Measurement of the current integral $\mathrm{T}_{\mathrm{sr}}$ int $_{\text {int }}$ and current change $\mathrm{T}_{\mathrm{sr} \text { iDif }}$ begins after the current value matches $75 \%$ of its assumed value. Following this filtered values of the steady state current $R_{\mathrm{s}_{-} 2}$ and voltage $\mathrm{R}_{\mathrm{s}_{-} \mathrm{u} 2}$ are obtained at the end of the interval. The resulting stator resistance $R_{\mathrm{sx}}$ and shunt time constant $T_{\mathrm{srx}}$ are then evaluated by relations:

$$
\begin{gathered}
R_{s x}=\left(\frac{R_{s_{-} u 1}}{R_{s_{-} i 1}}+\frac{R_{s_{-} u 2}}{R_{s_{-} i 2}}\right) / 2 \\
T_{s r x}=\frac{T_{s r_{-} i n t}}{T_{s r_{-} i D i f}}
\end{gathered}
$$

And again should be rescaled:

$$
R_{s}=R_{s x} \cdot \frac{s_{u}}{s_{i}}, T_{s r}=\frac{T_{s x x}}{f_{v}}
$$

For calculating the rest of equivalent circuit parameters following relations are utilized:

$$
\begin{gathered}
R_{\text {rref }}=\frac{L_{\sigma}}{T_{k}}-R_{s} \\
L_{\mu}=\frac{T_{s r} \cdot R_{s} \cdot R_{r}}{R_{s}+R_{r}} .
\end{gathered}
$$

\section{RESULTS}

Proposed method has been examined on a real drive with an induction motor. The drive consisted of a rectified power source, a power inverter, a three phase induction motor and a controller based on EKTM4C123GXL development board. Measurement has been implemented within the controller program.

TABLE I. INDUCTION MOTOR NOMINAL VALUES

\begin{tabular}{|l|l|l|}
\hline Type & 1 AY112L-L & \\
\hline$P_{n}$ & $3,5 \mathrm{~kW}$ & Nominal power \\
\hline $\mathrm{U}_{\mathrm{n}}$ & $380 \mathrm{~V}$ & Nominal voltage \\
\hline $\mathrm{I}_{\mathrm{n}}$ & $11 \mathrm{~A}$ & Nominal current \\
\hline $\cos \varphi$ & 0,6 & $\begin{array}{l}\text { Nominal power } \\
\text { factor }\end{array}$ \\
\hline $\mathrm{n}_{\mathrm{n}}$ & $960 \cdot 1 / \mathrm{min}$ & Nominal speed \\
\hline $\operatorname{connection}$ & $\mathrm{Y}$ & Star connected \\
\hline
\end{tabular}

Parameter values obtained by the offline method are presented in TABLE II. Comparison with the data obtained by standard tests is given. Measured waveforms for the first part of the method are 
presented in Figure 5. and Figure 6. show the current interval used for calculation as illustrated on Figure 4.

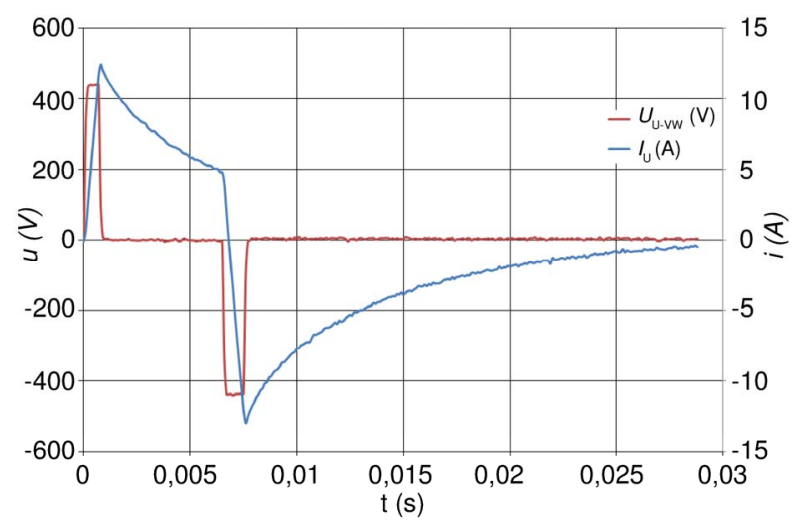

Figure 5. Time diagram of voltage and current measurement by the first part of the method

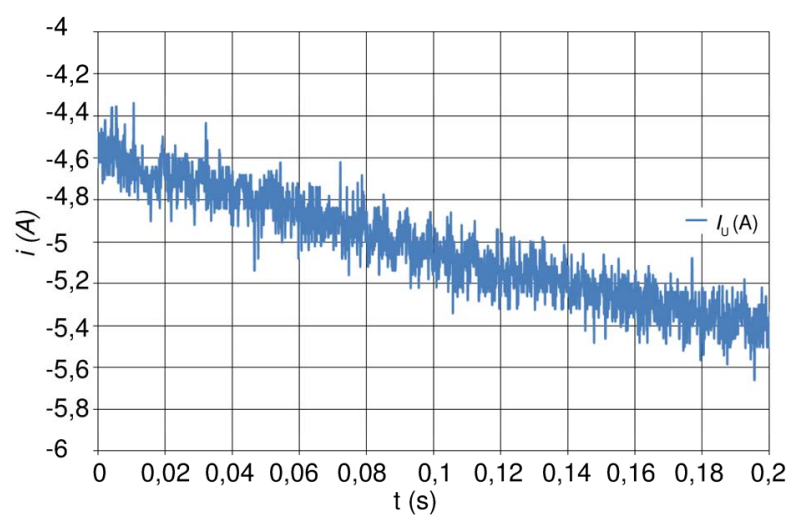

Figure 6. Interval of the stator current that was used for integral calculation during second part of the method

TABLE II. COMPARISON BETWEEN PARAMETERS OBTAINED BY STANDARD TESTS AND OFFLINE IDENTIFICATION METHOD

\begin{tabular}{|l|l|l|l|l|}
\hline Parameter & Unit & $\begin{array}{l}\text { Standard } \\
\text { test }\end{array}$ & $\begin{array}{l}\text { Offline } \\
\text { method }\end{array}$ & $\begin{array}{l}\text { Difference } \\
{[\%]}\end{array}$ \\
\hline $\mathrm{R}_{\mathrm{n}}$ & $\Omega$ & 1,1066 & 1,5700 & 41,9 \\
\hline $\mathrm{R}_{\mathrm{rref}}$ & $\Omega$ & 0,9790 & 0,7900 & $-19,3$ \\
\hline $\mathrm{L}_{\sigma}$ & $\mathrm{H}$ & 0,0165 & 0,0156 & $-5,2$ \\
\hline $\mathrm{L}_{\mu}$ & $\mathrm{H}$ & 0,0978 & 0,1347 & 37,7 \\
\hline
\end{tabular}

\section{CONCLUSION}

This paper concerns an offline parameter identification method suitable for self-commissioning of a drive that can obtain parameters needed for a mathematical model of a machine only by means of supplying power converter. Precise induction machine control methods like FOC and DTC use a mathematical model of the induction machine and thus require certain parameters of the model for proper operation.

Induction machine parameters can be obtained by laboratory measurements called standard tests which include DC test, no-load test and locked rotor test. These measurements require special equipment so they are not favorable for in-field commissioning of the electric drives. The demand for easy to use and fast manner of obtaining machine parameters aims on development of methods that can do this task only with the means of the power converter and the control system of the drive.

Presented offline identification method can fulfill the demands on self-commissioning of the drive as it uses only the converter and does not need to rotate with the machine. This permits the load to be connected to the drive and the method can be executed before every start of the operation.

Presented measurements on the $3,5 \mathrm{~kW}$ induction machine compared the data obtained by the offline method with the values gained by standard tests. It confirmed that the proposed offline identification method gives results sufficiently accurate to start the operation of the drive. However the achieved accuracy is lower than the natural variation of parameters between machines of the same type thus the type tests would be sufficient for such operation. When a drive is being commissioned the machine and a converter often come from different producers. In these cases the converter is connected to an "unknown" machine. In such cases the presented method is sufficient and useful. For drives with high demand on dynamic properties deployment of some further online method would be needed which would also respect the changes of the parameters during longer operation of the drive.

\section{ACKNOWLEDGMENT}

Research described in the paper was supported by the Grant Agency of the Czech Technical University in Prague, grant No. SGS17/089/OHK3/1T/13.

\section{REFERENCES}

[1] W. Michalik, "Parameter estimation methods at three-phase induction machines." In: 2005 European Conference on Power Electronics and Applications. IEEE, 2005, s. 10 pp.P.10 [cit. 2016-03-10]. DOI: 10.1109/EPE.2005.219603. ISBN 90-75815-09-3.

[2] W. Michalik, "Anwendung modemer Verfahren zur Parameterbestimmung an Asynchmnmaschinen.” Habilitationsschrift TU Dresden. 2003.

[3] "IEEE standard test procedure for polyphase induction motors and gener-ators,"IEEE Std 112-2004 (Revision of IEEE Std 112-1996), 2004.

[4] H. Toliyat, E. Levi, and M. Raina, "A review of RFO induction motor parameter estimation techniques," IEEE Trans. Energy Convers., vol. 18, no. 2, pp. 271-283, Jun. 2003.

[5] H. Schierling, "Self-commissioning - A novel feature of modern inverter-fed induction motor drives", Proceedings of Third International Conference on Power Electronics and Variable-Speed Drives, pp. 287-290, 1988.

[6] D. M. Reed, F. H. Hofmann, J. SUN, “Offline Identification of Induction Machine Parameters With Core Loss Estimation Using the Stator Current Locus" IEEE Transactions on Energy Conversion, vol. 31, no.4, p. 1549-1558, 2016.

[7] P. Vas, Parameter estimation, condition monitoring, and diagnosis of electrical machines, 360 p., New York: Oxford University Press, 1993.

KOŠŤÁL, T. "Offline Parameter Identification of an Induction Machine Supplied by Impressed Stator Voltages", Proceedings of the 20th International Scientific Student Conferenece POSTER 2016, Praha, 2016. 